\title{
Spatial-temporal variations in cold surge events in northern China during the period 1960-2016
}

\author{
GAO Wenlan, "DUAN Keqin, LI Shuangshuang \\ School of Geography and Tourism, Shaanxi Normal University, Xi'an 710119, China
}

\begin{abstract}
Among the most devastating extreme weather events, cold surge (CS) events frequently impact northern China. It has been reported that extreme weather events will increase in the global warming context. However, the direct evidence of this hypothesis is limited. Here, we investigated the changes in frequency, number, duration, and temperature of CS events in northern China using the daily minimum temperature dataset of 331 stations from 1960 to 2016. The results indicate that the annual CS events in terms of frequency and number decreased, and the duration shortened as the starting date was later and the ending date earlier. Meanwhile, the annual CS temperature increased. In addition, spatial trends in the CS events in terms of frequency, number, and duration decreased while the CS temperature increased in most regions of northern China. We interpreted these variations as a response to global warming. However, the extreme CS events in terms of frequency, number and the earliest starting date and the latest ending date showed little change though the extreme CS temperature increased, implying climate warming had not limited extreme CS events. The adverse effect of CS events on agriculture and human health remain concerning.
\end{abstract}

Keywords: cold surge; frequency; number; duration; temperature; northern China

\section{Introduction}

An increase in global mean surface air temperature has been detected over the past century (Hu et al., 2014; Gonzalez-Hidalgo et al., 2016; Yin et al., 2018). Compared to the mean climatic state, extreme climatic events are more sensitive to global warming (Aguilar et al., 2009; Ha and Yun, 2012; Schoetter et al., 2015; Lewis et al., 2017). Climate extremes have garnered much attention given their serious impacts on the ecological environment and human society (Braga et al., 2002; Trenberth, 2011; Leng et al., 2015; Gronlund et al., 2016; Jiang et al., 2018). During recent years, the world has been subject to unprecedented extreme weather events, such as a hailstorm in Eastern Brazil in 2016, an exceptionally cold episode on the Balkan Peninsula in 2017, and the earliest heatwave on record in western and central Europe

Received: 2018-05-29 Accepted: 2018-12-22

Foundation: National Natural Science Foundation of China, No.41571062, No.41701592

Author: Gao Wenlan (1985-), $\mathrm{PhD}$, specialized in global change and extreme climatic events. E-mail: gaowenlan1@126.com

*Corresponding author: Duan Keqin (1970-), Professor, specialized in global change and numerical simulation. E-mail: kqduan@snnu.edu.cn 
in 2017, resulting in destroyed forests, human casualties, and socioeconomic loss (Anagnostopoulou et al., 2017; Sánchez-Benítez et al., 2018; Servino et al., 2018). Thus, the analysis of extreme climatic events is absolutely necessary for risk mitigation and adaptation.

Among extreme climatic events, cold surge (CS) events are one of the most devastating hazards frequently occurring around the world such as in Europe, North America, and China (Lhotka and Kysely, 2015; Screen et al., 2015; Tao et al., 2017). Regarding northern China, there have been many studies regarding the number of CS occurrences. For example, Wei and Lin (2009) found that the number of CS events decreased during the period 1960-2001 in northern China. Meng et al. (2013) studied the spatial and temporal characteristics of CS events in northeastern China and determined that the number of CS events decreased during the period 1960-2010. Chen et al. (2010) examined the variation in the number of CS occurrences in Ningxia during the period 1961-2008, showing a decreasing trend and differences among seasons and regions. Liu et al. (2015) examined the spatio-temporal change in the number of CS events in Inner Mongolia and found a significant decrease occurred during the period 1960-2012 while a slight increase occurred during the period 1991-2012. In addition, Dong et al. (2017) discussed the starting date and ending date of CS occurrences in Shandong Province.

However, there have been few systematic studies of the characteristics of CS events. Previous studies have mainly focused on the number of CS events and several have discussed their duration. Less have addressed CS events in terms of frequency and temperature. In addition, the study areas of the existing articles mainly focus on parts of northern China. Few discuss northern China as a whole. Moreover, these early studies do not reflect the latest variations in CS events because they have not been updated with current observational data.

The objective of this study was to examine the spatial and temporal variations in CS events in terms of four aspects, i.e. frequency, number, duration, and temperature, based on daily minimum temperature data from northern China during the period 1960-2016. The impacts of CS events on agriculture and human health were also discussed.

\section{Data and method}

\subsection{Data}

Northern China is a part of China, lying north of $35^{\circ} \mathrm{N}$. CS events series were derived from the daily minimum temperature dataset recorded at 331 meteorological stations across northern China (Figure 1). CS events typically occur between September and May. Thus, we define an entire CS year as from September to the following May. Temperature data from September 1st, 1960 to May 31st, 2017 were used. The dataset for the period 1960-2013 was homogenized by Li et al (2016) using the Multiple Analysis of Series for Homogenization (MASH) method. After 2013, the temperature dataset was downloaded from the China Meteorological Data Service Center. The dataset was directly updated to 2017 in northern China.

\subsection{Method}

\subsubsection{Definition of CS events}

CS events can be defined based on the daily minimum temperature and its magnitude of de- 


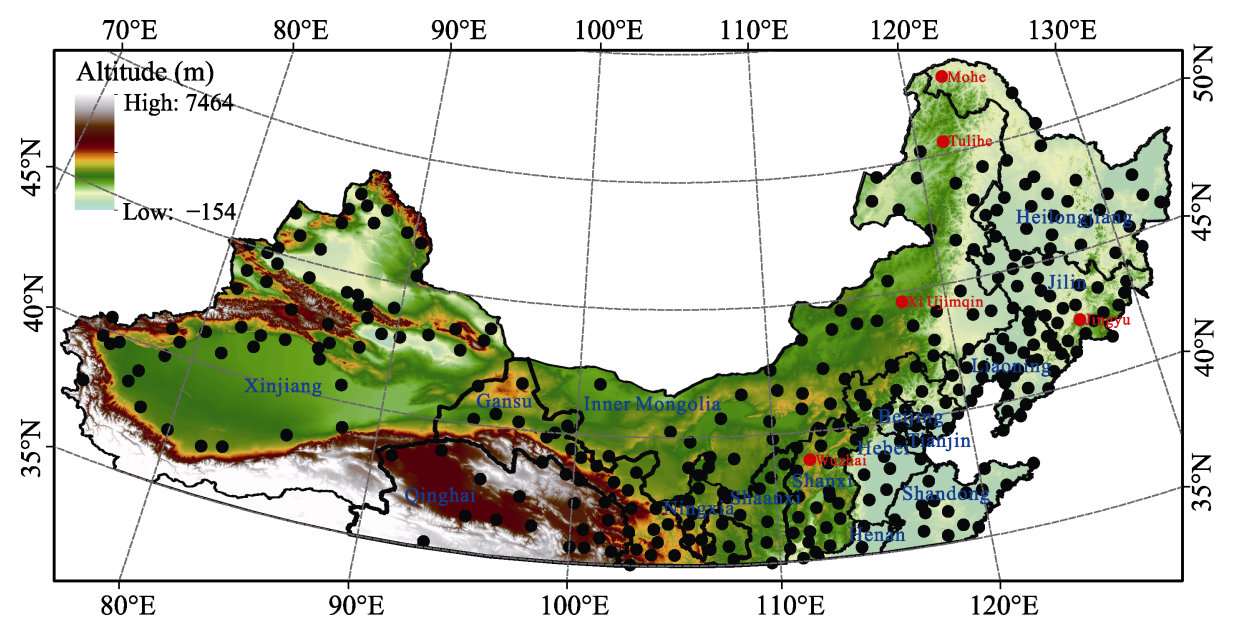

Figure 1 Distribution of meteorological stations in northern China. The black circles and red circles represent meteorological stations. The blue text represent provinces and the red text are meteorological station names.

crease according to the China Meteorological Administration. Minimum temperature data can better reflect daily temperature variations and it is not affected by solar radiation (Qian and Zhang, 2007). In this study, we mainly focused on CS events at a single station. The criterion for a CS event at a single station is (1) the daily minimum temperature is less than $4^{\circ} \mathrm{C}$, and (2) the decrease in daily minimum temperature is greater than $8^{\circ} \mathrm{C}$ within $24 \mathrm{~h}$, greater than $10^{\circ} \mathrm{C}$ within $48 \mathrm{~h}$, or greater than $12^{\circ} \mathrm{C}$ within $72 \mathrm{~h}$.

\subsubsection{Frequency, number, duration and temperature of CS events}

The spatial and temporal characteristics of CS events are quantified using four aspects: frequency, number, duration, and temperature, namely CS frequency, CS number, CS duration, and CS temperature, respectively (Table 1).

Table 1 Definition of CS events in terms of frequency, number, duration, and temperature

\begin{tabular}{llc}
\hline \multicolumn{1}{c}{ Items } & \multicolumn{1}{c}{ Definition } & Units \\
\hline CS frequency & Number of participating days according to CS events & Day \\
CS number & Number of CS events & Time \\
CS duration & $\begin{array}{l}\text { Number of days between the first day and the last day according to CS } \\
\text { events in a CS year }\end{array}$ & Day \\
CS temperature & Daily minimum temperature of CS events & ${ }^{\circ} \mathrm{C}$ \\
\hline
\end{tabular}

\subsubsection{Spatial and temporal variations in CS events in northern China}

Annual series of CS events in terms of frequency, number, duration, and temperature were calculated by the station average in northern China, respectively. Annual series of extreme values for frequency, number, and duration were directly selected from 331 stations of which one has the maximum value for each year, while annual series of extreme CS temperature were selected as the minimum values from 331 stations for each year. In addition, the annual series of starting date and ending date and the earliest starting date and the latest ending date of CS events were also calculated. 
The linear trends of temporal variations in CS events in terms of frequency, number, duration, and temperature were calculated using ordinary least squares regression. The annual value and annual extreme value of four parameters in the CS events were analyzed. The trends were tested using a t test at a 0.05 statistically significant level. The decadal changes of the four parameters of the CS events were compared for five periods, i.e. 1960-1970, 1971-1980, 1981-1990, 1991-2000, and 2001-2016.

The spatial distribution shows the average values of the CS events in terms of frequency, number, duration, and temperature for the period 1960-2016 at 331 individual stations. The average values of the starting date and ending date of CS events are also shown. The spatial trend reflects the tendency of CS events on a decadal scale. The linear trends of the CS events in terms of frequency, number, duration, and temperature at each station were also calculated using ordinary least squares regression for the period 1960-2016. A total of 331 stations' parameters were calculated and tested using a t test at a 0.05 significance level. The spatial distribution and trend were interpolated using the inverse distance weighted (IDW) method.

\section{Changes in CS events in northern China}

\subsection{Temporal variations in CS events}

\subsubsection{Annual variations in CS events}

During the period 1960-2016, the CS frequency decreased at a rate of -0.62 days/10a in northern China, and the long-term trend was statistically significant. Annual CS frequency first decreased and then slightly fluctuated (Figure 2a). The average CS frequencies were 13.63, 12.07, 10.47, 10.76, and 10.41 days per year during the periods 1960-1970, 1971-1980, 1981-1990, 1991-2000, and 2001-2016, respectively (Table 2).

The CS number decreased at a rate of -0.38 times/10a in northern China and the trend was statistically significant during the period 1960-2016 (Figure 2b). The annual CS number decreased during the period 1960-1985 and then slightly fluctuated. The average CS numbers were $9.06,8.23,7.27,7.31$, and 7.16 times per year during the periods 1960-1970, 1971-1980, 1981-1990, 1991-2000, and 2001-2016, respectively (Table 2).

The long-term trend in CS duration was significant at a rate of -4.79 days/10a during the period 1960-2016. The CS duration rapidly decreased during the period 1960-1990 and then slightly fluctuated (Figure 2c). The average CS durations were 169.53, 163.47, 150.75, 151.69, and 148.44 days per year during the periods 1960-1970, 1971-1980, 1981-1990, 1991-2000, and 2001-2016, respectively (Table 2). In addition, the annual average starting date and ending date of the CS events were examined (Figure 3). The starting date changed from mid-October to early November during the period 1960-2016. The ending date changed from mid-April to mid-March. The later starting date and earlier ending date of the CS events shortened the CS durations.

The CS temperature significantly increased at a rate of $0.33^{\circ} \mathrm{C} / 10 \mathrm{a}$ during the period 1960-2016 (Figure 2d). The average CS temperatures were $-12.97,-12.33,-12.57,-11.83$, and $-11.31^{\circ} \mathrm{C}$ per year during the periods $1960-1970,1971-1980,1981-1990,1991-2000$, and 2001-2016, respectively (Table 2). 

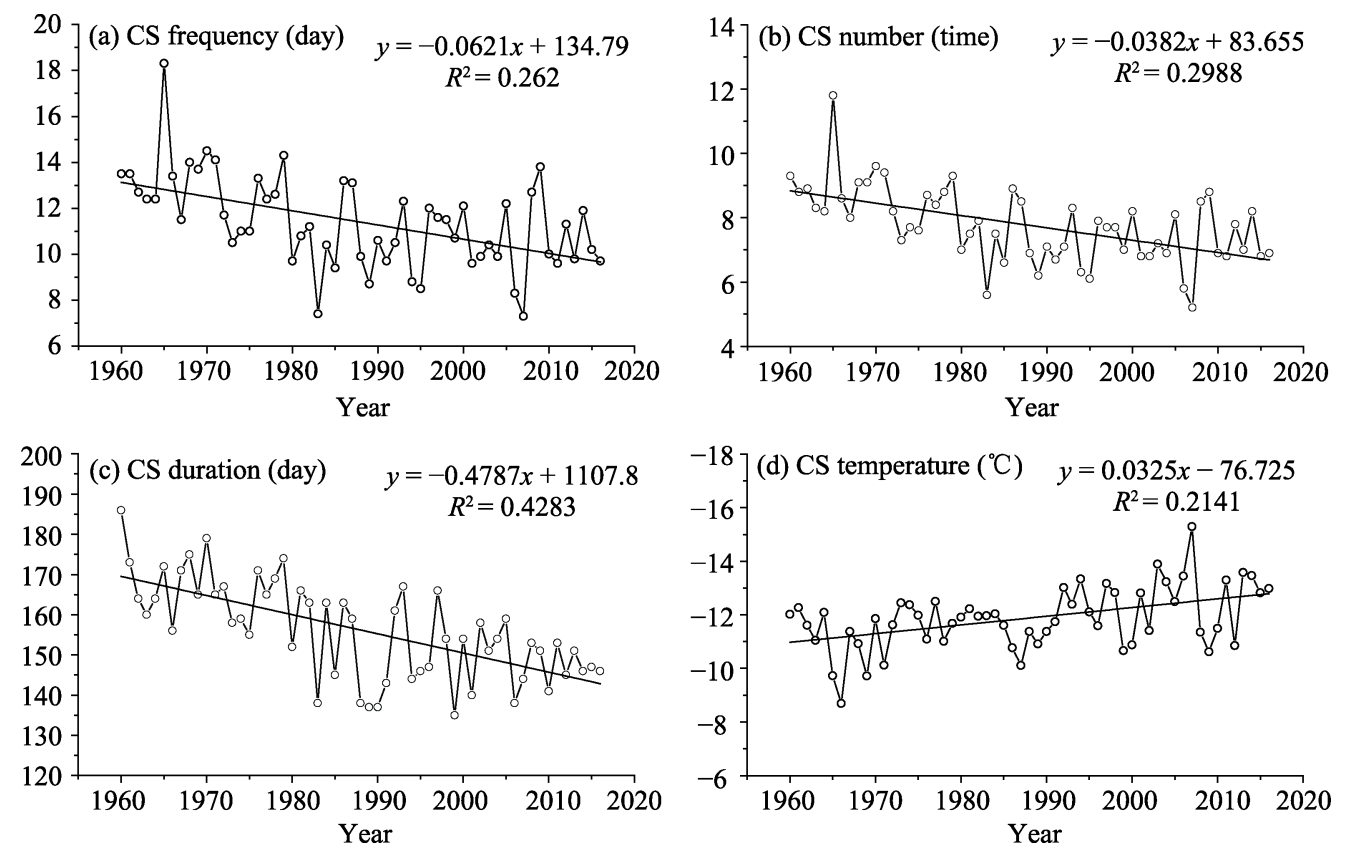

Figure 2 Annual variations in CS events in northern China during the period 1960-2016. The marked circles are annual values, and black lines are linear trends.
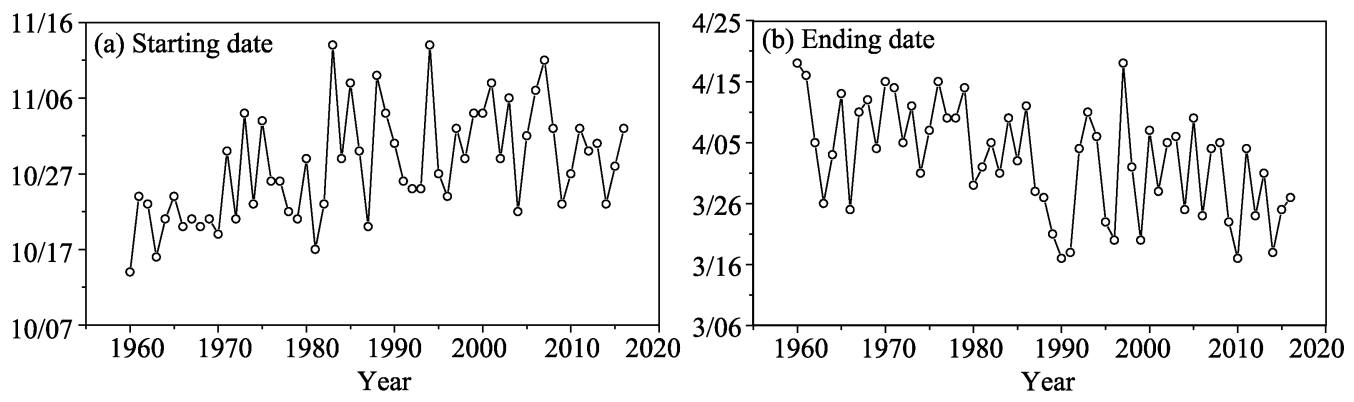

Figure 3 Annual variations in the starting date and ending date of CS events in northern China during the period 1960-2016. The marked circles are the dates of the CS occurrences.

Table 2 Decadal variations in CS events in terms of frequency, number, duration, and temperature

\begin{tabular}{lccccc}
\hline \multicolumn{1}{c}{ Items } & $1960-1970$ & $1971-1980$ & $1981-1990$ & $1991-2000$ & $2001-2016$ \\
\hline CS frequency (days per year) & 13.63 & 12.07 & 10.47 & 10.76 & 10.41 \\
CS number (times per year) & 9.06 & 8.23 & 7.27 & 7.31 & 7.16 \\
CS duration (days per year) & 169.53 & 163.47 & 150.75 & 151.69 & 148.44 \\
CS temperature ( ${ }^{\circ} \mathrm{C}$ per year) & -12.97 & -12.33 & -12.57 & -11.83 & -11.31 \\
\hline
\end{tabular}

\subsubsection{Annual variations in extreme value in CS events}

To analyze the changes in extreme CS events under global warming, the annual extreme values of the CS events in terms of frequency, number, duration, and temperature were calculated. The tendency of the annual maximum CS frequency gradually decreased insignificantly in northern China during the period 1960-2016. The maximum frequency slightly fluctuated during the period 1960-2016 (Figure 4a). The maximum value of CS frequency, 
by 60 days, was at Tulihe station in Inner Mongolia in 2010.

The annual maximum CS number insignificantly increased at a rate of 0.12 times/10a. The maximum number decreased during the period 1960-1973, then rapidly increased during the period 1974-1979, and thereafter slightly fluctuated (Figure 4b). The maximum value of the CS number, 41 times, occurred at Jingyu station in Jilin Province in 1979.

During the past 57 years, the annual maximum CS duration insignificantly decreased at a rate of -0.78 days/10a (Figure $4 \mathrm{c}$ ). The peak value of the CS duration occurred at Wuzhai station in Shanxi Province in 1989 and at Xi Ujimqin station in Inner Mongolia in 2011, both at 272 days. Additionally, the earliest starting date of CS events was mainly during early September and the latest ending date was mainly during late May (Figure 5). The earliest starting date and the latest ending date changed little.
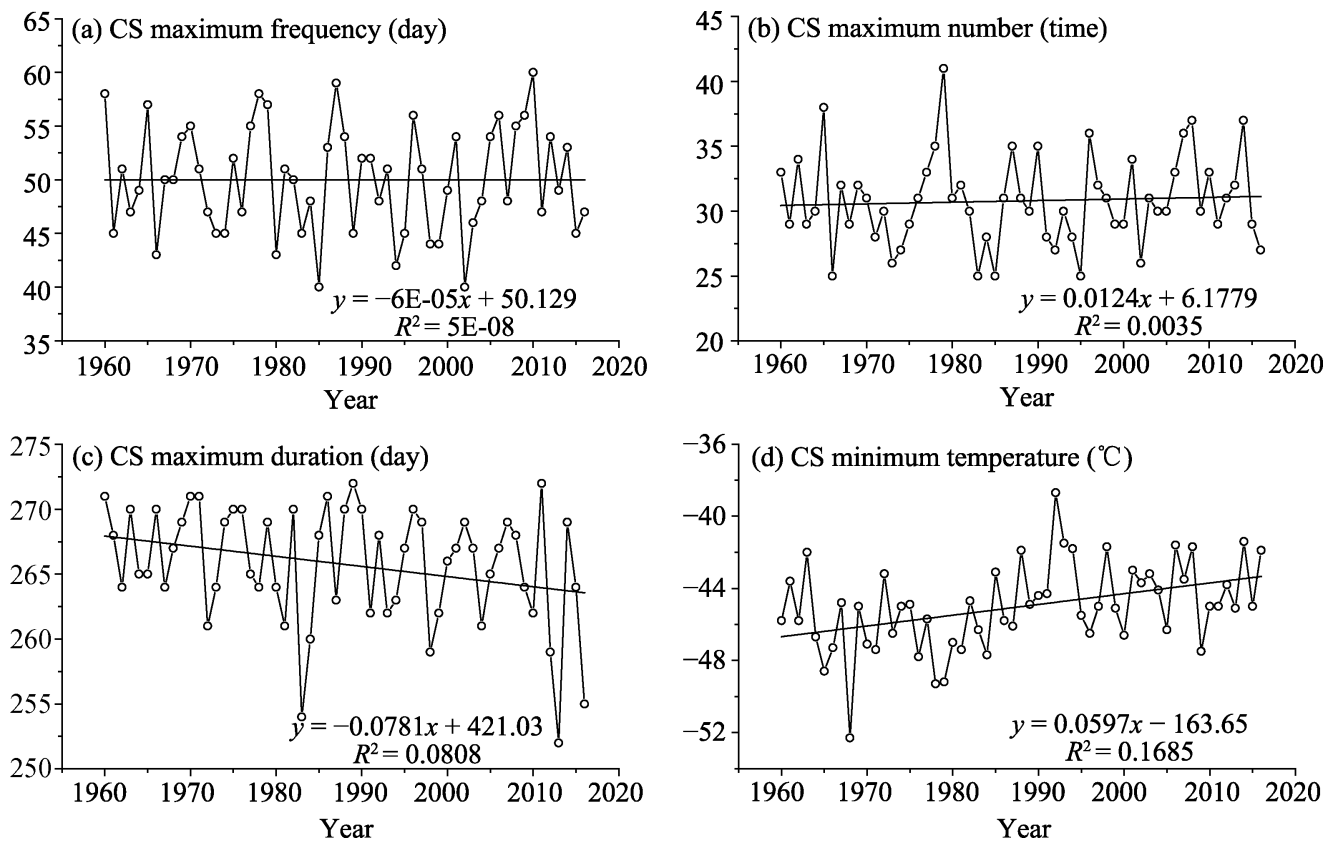

Figure 4 Annual variations in the extreme value in CS events in northern China during the period 1960-2016. The marked circles are annual extreme values, and the black lines are linear trends.
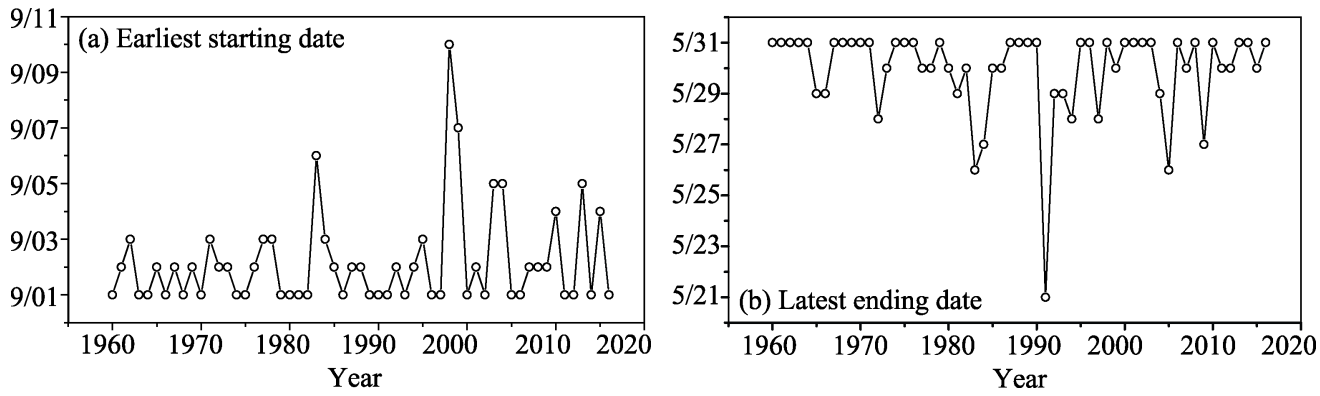

Figure 5 Annual variations in the earliest starting date and the latest ending date of CS events in northern China during the period 1960-2016. The marked circles are the dates of CS occurrence.

During the period 1960-2016, the annual minimum CS temperature significantly increased at $0.60^{\circ} \mathrm{C} / 10 \mathrm{a}$. The minimum $\mathrm{CS}$ temperature decreased during the period 
1960-1979, and then increased during the period 1980-1992; thereafter, it slightly fluctuated (Figure $4 \mathrm{~d}$ ). The minimum value of the CS temperature, $-52.30^{\circ} \mathrm{C}$, occurred at Mohe station in Heilongjiang Province in 1968.

\subsection{Spatial characteristics of CS events}

\subsubsection{Spatial distribution of CS events}

During the period 1960-2016, the annual average CS frequency was higher in northeastern China and northern Xinjiang, and lower in the central and eastern parts of northern China and southern Xinjiang (Figure 6a). In northernmost Heilongjiang, northernmost Inner Mongolia, and eastern Jilin, the CS frequency was more than 30 days per year. In northeastern China excluding the Sanjiang and Northeast China plains, northern Shanxi, and northern Xinjiang, the CS frequency was mainly greater than 15 days per year. In southern Xinjiang, southern Gansu, southern Hebei, northern Henan and eastern Shandong, the CS frequency was less than 5 days per year. At Jingyu station in Jilin, the CS frequency was the greatest, with an annual average of 46 days.

The distribution of the annual average CS number was similar to that of the CS frequency. The annual average CS number was higher in northeastern China, central Inner Mongolia, and northern Xinjiang, whereas it was lower in southern Xinjiang and central and eastern northern China (Figure 6b). The annual average CS number was greater than 18 times in northernmost Heilongjiang and Inner Mongolia and eastern Jilin. In most parts of Heilongjiang, Jilin, Liaoning, Inner Mongolia, northern Shanxi, and northern Xinjiang, the CS number was more than 9 times per year. The annual average CS number was less than 3 times mainly in southern Xinjiang, southern Hebei, northern Henan, and eastern Shandong. At Jingyu station in Jilin, the CS number was the highest, with an annual average of 29 times.

During the past 57 years, the CS duration was longer in the north than in the south as shown in Figure 6c. In most parts of Inner Mongolia, northern Heilongjiang, most parts of Jilin, northern Liaoning, and northern Xinjiang, the CS duration was longer than 190 days per year. The annual average CS duration was longer than 100 days in most regions of northern China. In southwestern Xinjiang and easternmost Shandong, the CS duration was shorter than 70 days per year. At Tulihe station in Inner Mongolia, the CS duration was the longest, at an annual average of 249 days.

Moreover, the starting date of the CS events was earlier in the north than in the south (Figure 7a). The CS events started during September in central and eastern Inner Mongolia and northernmost Heilongjiang, occurring later during October and November in most parts of Inner Mongolia, most regions of Heilongjiang, Jilin, Liaoning, northern Hebei, northern Shanxi, northern Shaanxi, western Gansu, and northern Xinjiang. Meanwhile in western Xinjiang, the starting date was delayed until December and January. The ending date of the CS events was earlier in western Xinjiang and later in northeastern China and most regions of the central and western parts of northern China (Figure 7b). The CS events ended during May in central and eastern Inner Mongolia and northernmost Heilongjiang, and during March and April in some regions of Inner Mongolia, most parts of Heilongjiang, Jilin, northern Liaoning, western Gansu, northern Qinghai, and northern Xinjiang. In western 
Xinjiang, the ending date mainly occurred during January and February.

The CS temperature was lower in the northern part of northeastern China and northern Xinjiang, but higher in southern Xinjiang and the southeastern part of northern China (Figure 6d). The CS temperature was lower than $-20^{\circ} \mathrm{C}$ per year mainly in northernmost Heilongjiang and Inner Mongolia. In southern Xinjiang, southern Shanxi, most parts of Hebei, northern Henan, and Shandong, the CS temperature was higher than $-7^{\circ} \mathrm{C}$ per year. In most regions of northern China, the annual average CS temperature was lower than $-10^{\circ} \mathrm{C}$. At Mohe station in Heilongjiang, the CS temperature was the lowest, at an annual average of $-26.5^{\circ} \mathrm{C}$ during the period $1960-2016$.
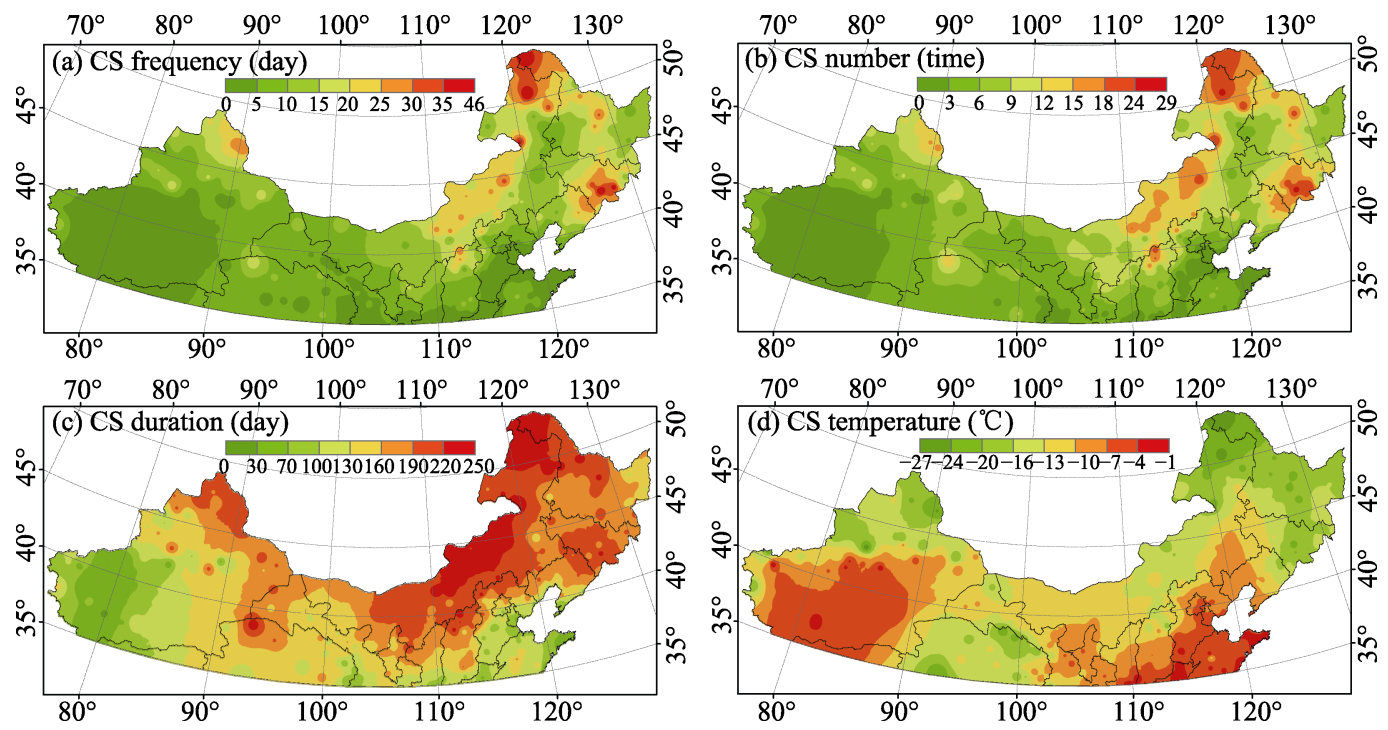

Figure 6 Spatial distribution of CS events in northern China during the period 1960-2016
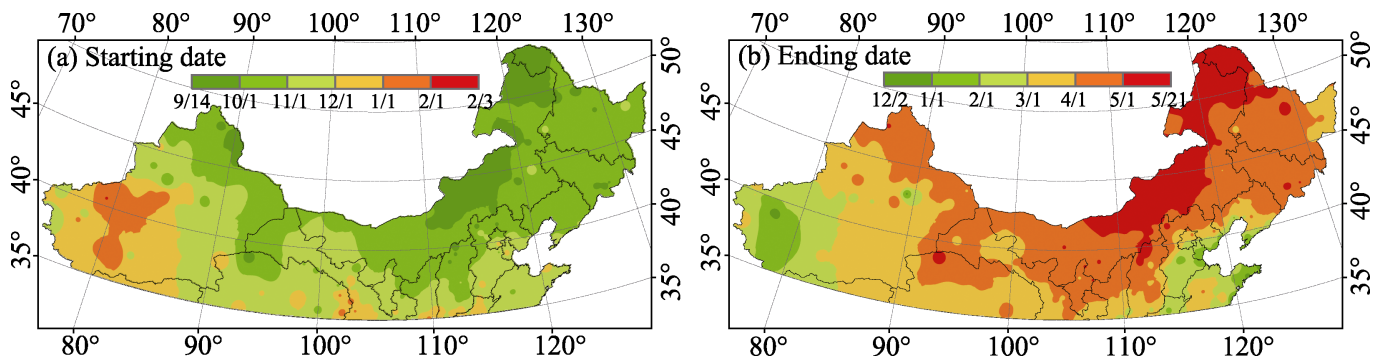

Figure 7 Spatial distribution of the starting date and ending date of mean CS events in northern China during the period 1960-2016

\subsubsection{Spatial trend in CS events}

During the period 1960-2016, the CS frequency varied at rates of -4.89 to 1.83 days/10a (Figure 8a). The CS frequency at most stations decreased across northern China, accounting for $82.18 \%$ of the total number of the stations. Also, 145 out of 272 negative trend stations significantly decreased. In northern and eastern Xinjiang, western Qinghai, and most areas in the eastern part of northern China, the CS frequency significantly decreased at a rate of less than -0.50 days/10a. In addition, at 59 increasing stations of CS frequency, 11 stations 
significantly increased, accounting for $3.32 \%$ of the stations. The uptrend stations were scattered across northern China.

The CS number varied at rates of from -3.81 to 1.24 times/10a in northern China during the period 1960-2016 (Figure 8b). The CS number decreased at most stations across northern China, accounting for $80.36 \%$ of the stations, and 150 out of 266 negative trend stations significantly decreased. Similar to the CS frequency, a significant decreasing trend in the CS number occurred in eastern Xinjiang, western Qinghai, and most regions in the eastern part of northern China, at a rate of less than -0.50 times/10a. In addition, at 65 of the increasing CS number stations, 18 stations significantly increased, accounting for $5.44 \%$ of the stations. The stations with an increasing trend were also scattered throughout northern China.

The CS duration varied at rates of from -30.41 to 18.19 days/10a in northern China during the period 1960-2016 (Figure 8c). The CS duration at 275 stations decreased across northern China, accounting for $83.08 \%$ of the stations, while only 117 stations significantly decreased. The stations with significant decreasing trends of less than -5.00 days/10a were mainly in the western part of northern China, some parts of Inner Mongolia, southern Heilongjiang, most parts of Jilin, Liaoning and Shandong. At 56 increased CS duration stations, only 5 stations significantly increased, accounting for $1.51 \%$ of the stations.

The CS temperature varied at rates of from -0.75 to $2.08^{\circ} \mathrm{C} / 10 \mathrm{a}$ in northern China during the period 1960-2016 (Figure 8d). The CS temperature increased at most stations across northern China, accounting for $87.01 \%$ of the stations, and 79 out of the 288 positive trend stations significantly increased. The decreased CS temperature stations were scattered throughout northern China. At 43 decreased CS temperature stations, only 2 stations significantly decreased, accounting for $0.60 \%$ of the stations.
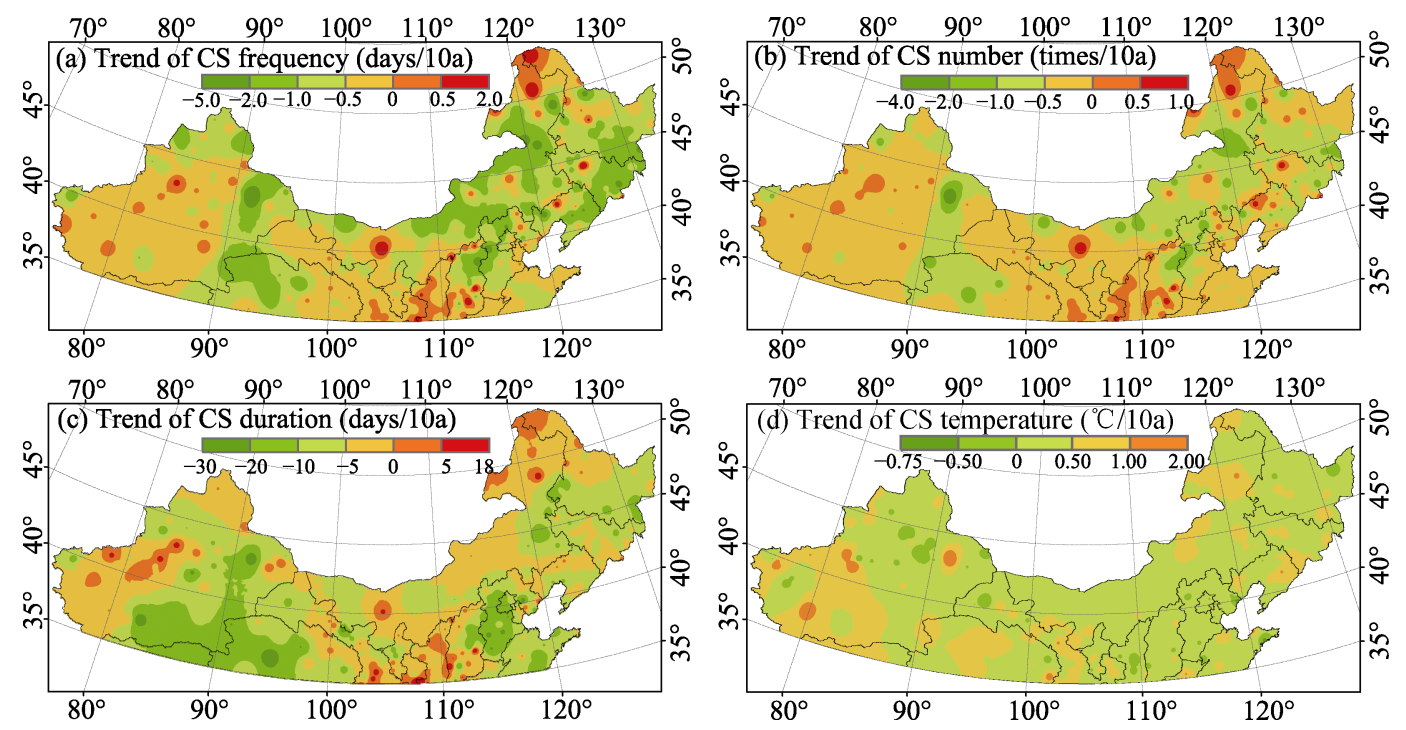

Figure 8 Spatial trends of CS events in northern China during the period 1960-2016

\subsection{Impacts of CS events on agriculture and human health}

\subsubsection{Agriculture affected by CS events}

$\mathrm{CS}$ events are accompanied by low temperature, and sometimes snow. According to the ag- 


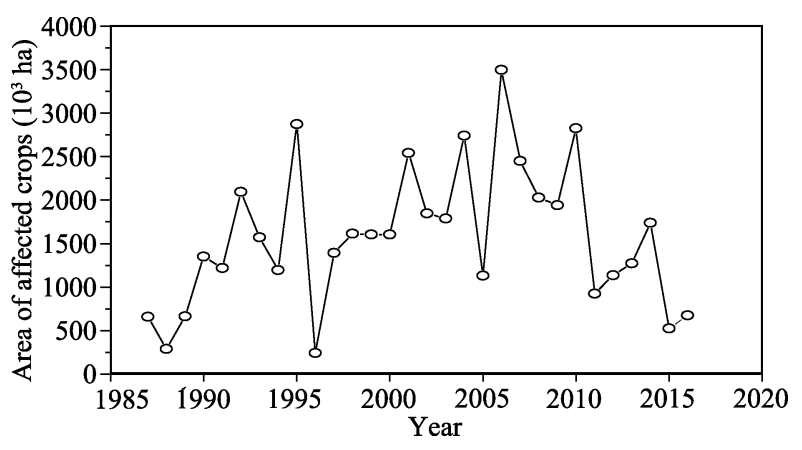

Figure 9 Area of affected crops in northern China during the period 1987-2016 ricultural statistics of China from 1987 to 2016 (MAC, 1988-2017), the area of crops affected by low temperatures and snow in northern China was determined (Figure 9). During the past 30 years, the area of affected crops was approximately 42 million hectares in total, with an annual average of approximately 1.4 million hectares. The area of affected crops increased from 1987 to 2006 and then decreased during the period 2007 2016. In 2006, northern China had the largest area of affected crops at approximately 3.4 million hectares.

\subsubsection{Human health risk caused by CS events}

At extreme low temperatures, human beings are likely subject to frostbite or illness, particularly those exposed to the outdoors. The relationship between extreme low temperature and human mortality risk in China during the period 2007-2012 was discussed by Wang et al. (2017). In their study, the mid-subtropical zone of China had the greatest health risk of 1.93, followed by the warm-temperate zone and the middle-temperate zone. Because most areas of northern China are in the warm-temperate and middle-temperate zones, the relative risk to human health was high. The spatial distribution of the relative risk to human health showed that the risk was higher in southern Xinjiang and the central and eastern parts of northern China, with a relative risk of 1.78 . In the middle-temperate zone of northern China, the relative risk to human health was 1.61 (Figure 10).

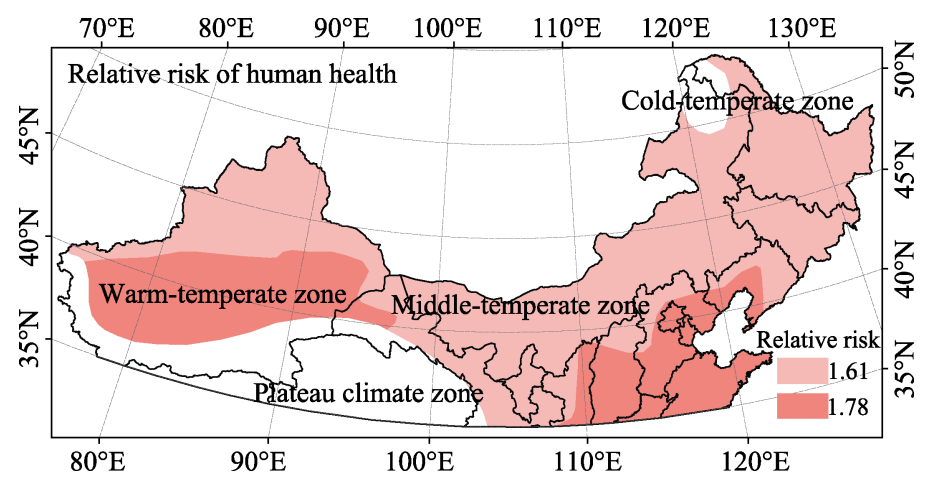

Figure 10 Spatial distribution of the relative risk to human health in northern China during the period 2007-2012. This figure was redrawn from Wang et al., 2017. The relative risk in the cold-temperate zone and the plateau climate zone was not analyzed in their study.

\section{Discussion and conclusions}

\subsection{Discussion}

In the present study, the annual CS events decreased in terms of frequency, number, and du- 
ration and increased in terms of temperature in most regions of northern China in response to climate warming. Numerous studies have confirmed that CS events in terms of frequency and number have decreased in most parts of China (Wang and Ding, 2006; Ding et al., 2009; Luo et al., 2017b). The annual CS duration in northern China significantly decreased. Dong et al. (2017) found that CS starting dates occurred later and the ending dates earlier in Shandong Province, a finding consistent with that in northern China. However, few studies have analyzed CS temperature. The CS temperature increase in northern China during the period 1960-2016 was in line with decrease in the CS frequency, number and duration.

Notably, an intriguing finding was that global warming had not reduced extreme CS occurrences. Though the extreme CS temperature increased, the extreme value of CS events in terms of frequency, number, and the earliest starting date and the latest ending date showed little change. The annual extreme CS duration decrease was relatively minor. It seems that the warmer climate has not limited extreme CS occurrences. Numerous studies have discussed rapid Artic warming and related sea ice loss possibly contributing to an increase in extreme cold events (Honda et al., 2009; Inoue et al., 2012; Cohen and Coauthors, 2014; Johnson et al., 2018). Arctic warming has weakened the meridional temperature gradient in the mid-high latitudes of Eurasia and decreased the strength of the mean westerly wind and its vertical shear, intensifying the quasi stationarity and persistence of the Ural blocking (Yao et al., 2017). This quasi stationarity of the Ural blocking could transport cold air from high latitudes to Eurasian mid-latitudes, leading to more extensive cold events in Eurasia (Luo et al., 2017a). However, whether the variability in the extreme CS events in northern China is related to Arctic warming remains unknown, and will be a key point of further discussion.

In addition, considering the adaptation and vulnerability of living things to temperature variation, a sudden decrease in temperature may be more harmful to ecosystems and human beings. In the context of global warming, living beings are constantly adapting to warming temperatures, resulting in a decline in ability to resist cold temperatures. Large areas of affected crops and a high risk to human health are responses to cold extremes. In our study, we only discussed crop loss and human health risk. Further examination of the impact of extreme cold events on ecosystem components such as vegetation, hydrology, etc. is needed.

\subsection{Conclusions}

The spatial and temporal variations in CS events in terms of frequency, number, duration, and temperature were systematically analyzed based on observational station temperature data in northern China during the period 1960-2016. The influence of CS events on agriculture and human health was discussed. The major findings are as follows:

(1) During the period 1960-2016, the annual CS events in terms of frequency and number significantly decreased at rates of -0.62 days $/ 10 \mathrm{a}$ and -0.38 times/10a, respectively. The CS duration decreased at a rate of -4.79 days/10a, as the starting date occurred later and the ending date earlier in time. Meanwhile, the CS temperature significantly increased at a rate of $0.33^{\circ} \mathrm{C} / 10 \mathrm{a}$. For extreme value of CS events, the maximum CS frequency showed little change. The maximum CS number slightly increased to 0.12 times/10a. The maximum CS duration insignificantly decreased to -0.78 days $/ 10 \mathrm{a}$, owing to the slight change in the earliest starting date and the latest ending date. The extreme CS temperature significantly in- 
creased to $0.60^{\circ} \mathrm{C} / 10 \mathrm{a}$.

(2) Spatially, distributions of CS events in terms of frequency, number, and duration were greater in northern Xinjiang and northeastern China, and less in southern Xinjiang and the central and eastern parts of northern China. The CS temperature was lower in northern Xinjiang and northeastern China, but higher in southern Xinjiang and the central and eastern parts of northern China. The CS events in terms of frequency, number, and duration decreased across most parts of northern China, while the CS temperature increased in most regions of northern China.

(3) The impact of CS events on agriculture showed that the area of affected crops was approximately 42 million hectares in total and approximately 1.4 million hectares as an annual mean during the period 1987-2016. During the extreme low temperature events, the relative risk to human health was 1.78 in the warm-temperate zone and 1.61 in the middle-temperate zone over northern China during the period 2007-2012.

\section{References}

Aguilar E, Barry A A, Brunet M et al., 2009. Changes in temperature and precipitation extremes in western Central Africa, Guinea Conakry, and Zimbabwe, 1955-2006. Journal of Geophysical Research, 114(D2): 356-360.

Anagnostopoulou C, Tolika K, Lazoglou G et al., 2017. The exceptionally cold January of 2017 over the Balkan Peninsula: A climatological and synoptic analysis. Atmosphere, 8(12): 252. doi: 10.3390/atmos8120252.

Braga A L F, Zanobetti A, Schwartz J, 2002. The effect of weather on respiratory and cardiovascular deaths in 12 US cities. Environmental Health Perspectives, 110(9): 859-863.

Chen Y L, Chen N, Ma J R et al., 2010. Variety of Ningxia cold waves in the last 48 years and its possible reasons. Journal of Natural Resources, 25(6): 939-951. (in Chinese)

Cohen J, Screen J A, Furtado J C et al., 2014. Recent Arctic amplification and extreme mid-latitude weather. Nature Geoscience, 7(9): 627-637.

Ding T, Qian W H, Yan Z W, 2009. Characteristics and changes of cold surge events over China during 1960-2007. Atmospheric and Oceanic Science Letters, 2(6): 339-344.

Dong S, Huang W N, Li X et al., 2017. Study on temporal and spatial characteristics of cold waves in Shandong Province of China. Natural Hazards, 88(1): 191-219.

Gonzalez-Hidalgo J C, Peña-Angulo D, Brunetti M et al., 2016. Recent trend in temperature evolution in Spanish mainland (1951-2010): From warming to hiatus. International Journal of Climatology, 36(6): 2405-2416.

Gronlund C J, Zanobetti A, Wellenius G A et al., 2016. Vulnerability to renal, heat and respiratory hospitalizations during extreme heat among US elderly. Climatic Change, 136(3): 631-645.

Ha K J, Yun K S, 2012. Climate change effects on tropical night days in Seoul, Korea. Theoretical and Applied Climatology, 109(1/2): 191-203.

Honda M, Inoue J, Yamane S, 2009. Influence of low Arctic sea-ice minima on anomalously cold Eurasian winters. Geophysical Research Letters, 36(8): 262-275.

$\mathrm{Hu}$ Z Y, Zhang C, Hu S Q et al., 2014. Temperature changes in Central Asia from 1979 to 2011 based on multiple datasets. Journal of Climate, 27(3): 1143-1167.

Inoue J, Masatake E H, Koutarou T, 2012. The role of Barents Sea ice in the wintertime cyclone track and emergence of a warm-Arctic cold-Siberian anomaly. Journal of Climate, 25(7): 2561-2568.

Jiang D, Xiao W H, Wang J H et al., 2018. Evaluation of the effects of one cold wave on heating energy consumption in different regions of northern China. Energy, 142: 331-338.

Johnson N C, Xie S P, Kosaka Y et al., 2018. Increasing occurrence of cold and warm extremes during the recent global warming slowdown. Nature Communications, 9(1): 1724. doi: 10.1038/s41467-018-04040-y.

Leng G Y, Tang Q H, Rayburg S, 2015. Climate change impacts on meteorological, agricultural and hydrological 
droughts in China. Global and Planetary Change, 126: 23-34.

Lewis S C, King A D, Perkins-Kirkpatrick S E, 2017. Defining a new normal for extremes in a warming world. Bulletin of the American Meteorological Society, 98(6): 1139-1151.

Lhotka O, Kyselý J, 2015. Characterizing joint effects of spatial extent, temperature magnitude and duration of heat waves and cold spells over Central Europe. International Journal of Climatology, 35(7): 1232-1244.

Li Z, Cao L J, Zhu Y N et al., 2016. Comparison of two homogenized datasets of daily maximum $/ \mathrm{mean} / \mathrm{minimum}$ temperature in China during 1960-2013. Journal of Meteorological Research, 30(1): 53-66.

Liu X F, Zhu X F, Pan Ya Z et al., 2015. Spatiotemporal changes of cold surges in Inner Mongolia between 1960 and 2012. Journal of Geographical Sciences, 25(3): 259-273.

Luo D H, Yao Y, Dai A G et al., 2017a. Increased quasi stationarity and persistence of winter ural blocking and eurasian extreme cold events in response to Arctic warming. Part II: A theoretical explanation. Journal of Climate, 30(10): 3569-3587.

Luo J, Dai J M, Yang H et al., 2017b. Climatic characteristics of cold wave in Xinjiang during the period of 1971-2014. Arid Zone Research, 34(2): 309-315. (in Chinese)

Meng X J, Wu Z F, Du H B et al., 2013. Spatio-temporal characteristics of cold wave over northeast China during 1961-2010. Journal of Arid Land Resources and Environment, 27(1): 142-147. (in Chinese)

Ministry of Agriculture of the People's Republic of China (MAC), 1988-2017. Agricultural Statistics of China. Beijing: Chinese Agricultural Press.

Qian W H, Zhang W W, 2007. Changes in cold wave events and warm winter in China during the last 46 years. Chinese Journal of Atmospheric Sciences, 31(6): 1266-1278. (in Chinese)

Sánchez-Benítez A, García-Herrera R, Barriopedro D et al., 2018. June 2017: The Earliest European summer mega-heatwave of reanalysis period. Geophysical Research Letters, 45(4):1955-1962.

Schoetter R, Cattiaux J, Douville H, 2015. Changes of western European heat wave characteristics projected by the CMIP5 ensemble. Climate Dynamics, 45(5/6): 1601-1616.

Screen J A, Deser C, Sun L T, 2015. Reduced risk of North American cold extremes due to continued Arctic sea ice loss. Bulletin of the American Meteorological Society, 96(9): 1489-1503.

Servino R N, Gomes L E D O, Bernardino A F, 2018. Extreme weather impacts on tropical mangrove forests in the eastern Brazil marine ecoregion. Science of the Total Environment, 628/629: 233-240.

Tao Y W, Dai K, Dong Q et al., 2017. Extreme analysis and ensemble prediction verification on cold wave process in January 2016. Meteorological Monthly, 43(10): 1176-1185. (in Chinese)

Trenberth K E, 2011. Changes in precipitation with climate change. Climate Research, 47(1): 123-138.

Wang B L, Zhang M J, Wei J L et al., 2013. Changes in extreme precipitation over Northeast China, 1960-2011. Quaternary International, 298(17): 177-186.

Wang C Z, Zhang Z, Zhou M G et al., 2017. Analyzing the spatial differences of the relationships between low temperature and health risk in China. Journal of Geo-information Science, 19(3): 336-345. (in Chinese)

Wang Z Y, Ding Y H, 2006. Climate change of the cold wave frequency of China in the last 53 years and the possible reasons. Chinese Journal of Atmospheric Sciences, 30(6): 1068-1076. (in Chinese)

Wei J H, Lin Z H, 2009. The leading mode of wintertime cold wave frequency in northern China during the last 42 years and its association with Arctic Oscillation. Atmospheric Oceanic Science Letters, 2(3): 130-134.

Yao Y, Luo D H, Dai A G et al., 2017. Increased quasi stationarity and persistence of winter Ural Blocking and Eurasian extreme cold events in response to Arctic warming (Part I): Insights from observational analyses. Journal of Climate, 30(10): 3549-3568.

Yin J J, Overpeck J T, Peyser C et al., 2018. Big jump of record warm global mean surface temperature in 2014-2016 related to unusually large oceanic heat releases. Geophysical Research Letters, 45(2): 1069-1078. 